\title{
Effect of in Service Weld Repair on the Performance of CrMo Steel Steam Pipelines
}

 \\ Sergio Haro Rodríguez, ${ }^{\mathrm{c}}$ Alejandro López Ibarra ${ }^{\mathrm{c}}$ \\ ${ }^{a}$ Centro de Investigaciones en Soldadura, Universidad Central "Marta Abreu” de Las Villas \\ Carretera a Camajuaní, Km 5 1⁄2, Santa Clara - VC, Cuba \\ ${ }^{\mathrm{b}}$ Departamento de Engenharia de Materiais, Universidade Federal de São Carlos, \\ Rodovia Washington Luis, Km 235, C. P. 676, 13565-905 São Carlos - SP, Brazil \\ 'Unidad Académica de Ingeniería, Universidad Autónoma de Zacatecas, \\ Av. Ramón López Velarde, 801, Zac. 98060 Zacatecas, México
}

Received: March 17, 2005; Revised: October 4, 2005

\begin{abstract}
This article presents a literature overview and discusses a practical case involving the effect of in service weld repair on the performance - behavior under creep conditions and remanent life - of low alloy CrMo steel steam pipelines with longstanding use. According to the specialized literature, several authors argue that the in service weld repair of low alloy CrMo steel steam pipes can be done successfully, while others disagree, reporting a reduction of up to $30 \%$ or more in the remanent life. According to the case analyzed here, which involves the weld repair of a $1 \frac{1}{4} \mathrm{Cr}^{1} / 2 \mathrm{Mo}$ ferrite-pearlite steel steam pipe operating for 20 years at $480{ }^{\circ} \mathrm{C}$, in service weld repair leads to the intragranular precipitation of $\mathrm{Fe}_{2} \mathrm{MoC}$-type carbides and decreases the solute concentration of the ferrite in the base metal adjacent to the welded joint, thereby considerably reducing the pipeline's remanent life, since the estimated rupture time for the service-aged material is 3.6 times that estimated for the weld-repaired joint.
\end{abstract}

Keywords: in service weld repair, steam pipe, remanent life, CrMo steel, creep

\section{Introduction}

Many industrial plants around the world, operating in the electric energy and the oil and oil by-products sectors, use equipment that has been in service for over twenty or even thirty years and the critical components of this equipment have exceeded their design-estimated service life. These components are frequently subjected to weld repair since, from the technological and economic standpoint, this is a viable procedure. However, no standards or specific procedures exist that allow weld repair technology to be selected or the subsequent performance of a repaired component to be predicted.

According to Viswanathan ${ }^{1}$, this situation may lead to unpredictable and undesirable consequences, such as lack of safety in service, risk of fatal accidents and substantial economic losses resulting from unforeseen stoppages caused by the inadequate performance of repaired components.

The specialized literature reports results indicating that weld repairs of service-aged low alloy CrMo ferritic steel steam pipes do not impair their subsequent performance ${ }^{2-5}$, while other results indicate the opposite ${ }^{6-8}$. According to Parker and Stratford ${ }^{9}$ and Shiga et al. ${ }^{10}$, this subject requires careful consideration in order to avoid generalizing results obtained under specific conditions.

The controversial nature of this subject has led to increasing interest in the development of scientific studies to record, characterize and understand the phenomena governing the behavior of important industrial components such as steam pipes after they have been subjected to weld repair. In this context, among the aspects of greatest interest is the analysis of the effect of weld repairs on the remanent life. That is the aspect involved in the study reported on here, which aimed to systematize the fundamental information published in the literature and to present its own case study-based results.

\section{In Service Steam Pipe Weld Repair and Remanent Life: A Literature Overview}

According to Shiga et al. ${ }^{10}$, the specialized literature offers insufficient reports concerning the effect of weld repair on the microstructure and subsequent performance of service-aged low alloy $\mathrm{CrMo}$ steel steam pipes.

Etienne et al. ${ }^{6}$ evaluated the possibility of localized repairs in steam feeders $\left(2^{1 / 4} \mathrm{Cr} 1 \mathrm{Mo}\right.$ steel) using manual welding with coated electrodes and arc welding with tungsten electrodes in a gaseous atmosphere with and without preheating and PWHT. In the second phase of their study, they applied the same experimental procedure to several welded joint regions, which displayed creep voids and cracks. The authors conducted creep rupture tests, applying a $45 \mathrm{MPa}$ stress, at temperatures of 625,650 and $675^{\circ} \mathrm{C}$, and extrapolated the results to estimate the remanent service life at the operating temperature. These authors attributed the reduction in remanent service life after weld repair to the incomplete extraction of damaged metal, but failed to make the corresponding corrections.

Viswanathan et al. ${ }^{2-4}$ compared the results of two cases of steam pipe weld repair: 1- localized repair of service-exposed weld joints $\left(2 \frac{1}{4} \mathrm{Cr} 1 \mathrm{Mo}\right.$ steel) using welding with coated electrode and PWHT, and 2- repair by the temperbead technique. These authors used various combinations of stress (from 55 to $162 \mathrm{MPa}$ ) and temperature $\left(565\right.$ to $650{ }^{\circ} \mathrm{C}$ ) to determine creep rupture time for the service-aged joint and the weld repaired joint. Based on their results, they established a correlation between the nominal stress and the Larson-Miller parameter, which then served as the basis for estimating the remanent life under the operating stress of each condition. The authors concluded that the repair by both methods 
could provide satisfactory results, since the remanent life estimated for the weld repaired joint was longer than that estimated for the service-aged joint, and because, in the former case, the rupture occurred consistently in the base metal while, in the latter, the rupture occurred in the weld metal.

Arnswald et al. ${ }^{7}$ studied the effect of weld repairs on the remanent life by applying the coated electrode process followed by PWHT of the base metal of steam pipes $\left(2 \frac{1}{4} \mathrm{Cr} 1 \mathrm{Mo}\right.$ steel). Extrapolating the creep rupture test results was estimated the remanent life for the base metal and for the weld repaired joints, concluding that the remanent life was reduced by $30 \%$ as a result of the repair procedure. This result was similar to that obtained earlier by these same authors using service-aged material; therefore, they generalized the conclusion that welding of both the original and the service-aged material led to a $30 \%$ reduction of its remanent life.

Westwood ${ }^{8}$ investigated weld repair with coated electrode and PWHT of new and in service-aged steam pipelines (21/4Cr1Mo and $1 \frac{1}{4} \mathrm{Cr}^{1} / 2 \mathrm{Mo}$ steel). Extrapolating the creep rupture test results (at a stress of $40 \mathrm{MPa}$ and temperatures of 600 to $650{ }^{\circ} \mathrm{C}$ ), Westwood ${ }^{8}$ concluded that the welded joints of both the new and the service-aged material showed a lower remanent life than the base metal (with a reduction factor of about 5). In the case of the welded joint of the service-aged material, the remanent life proved inferior to that of the welded joint of the original material (with a reduction factor of approximately 2.4 ).

Parker and Stratford ${ }^{9}$ reached an important conclusion regarding the heat treatment applied after in-service weld repair. According to them, the effect of the heat treatment after weld repair of stem pipes has not been studied sufficiently and, therefore, standards are in use today that covers a very ample range of temperatures. According to these authors' findings, heat treating after welding at 700,725 and $750{ }^{\circ} \mathrm{C}$ - all temperatures within the range recommended by manufacturing standards - lead to differences in behavior under creep conditions; therefore, they recommend new studies on this subject.

Lunding et al. ${ }^{5}$ evaluated the effect of welds repairs with a coated electrode, with and without PWHT, on the base metal and on the longitudinal weldment of $1 \frac{1 / 4}{\mathrm{Cr}} 1 / 2 \mathrm{Mo}$ steel steam pipelines. The creep tests they conducted on the base metal of the service-aged welded joint and on the weld repaired joint were carried out with various combinations of stress and temperatures (55 to $170 \mathrm{MPa}$ and 538 to $660{ }^{\circ} \mathrm{C}$ ). Under most of the testing conditions, the values of the Larson-Miller parameter were lower than the values of the reference curve. Nevertheless, the authors concluded that weld repairs could be applied satisfactorily.

According to the above cited studies, the weld repair of low alloy CrMo steel steam pipes that have been longtime in service can, in some cases, be carried out successfully, while in other cases, it may reduce a component's remanent service life. Furthermore, these studies highlight two important limitations that conditioned the generalization of the published results:

- The remanent life was estimated based on the extrapolation of a limited number of data, and without following common procedures insofar as the creep test and the statistical analysis of the results are concerned; and

- The correlation of the microstructure with the effect of the heating cycle of the weld repair was not sufficiently well established, making it difficult to understand the problem from the metallurgical standpoint.

Shiga et al. ${ }^{10}$ consider that question of the performance of welded joints in low alloy CrMo steel steam pipes in longstanding operation has not been sufficiently understood from the scientific standpoint, nor has it been solved from the technological point of view.

\section{In Service Steam Pipe Weld Repair and Remanent Life: A Case Study}

\subsection{Experimental work}

This study involved $150-\mathrm{mm}$ long cylindrical samples taken from a pipe which is part of a $300 \mathrm{~mm}$ diameter, $12 \mathrm{~mm}$ thick steam pipeline which had been in operation in a petrochemical plant for about 20 years at a temperature of $480{ }^{\circ} \mathrm{C}$.

The chemical composition of the pipeline material corresponds to that of $1 \frac{1}{4} \mathrm{Cr}^{1} / 2 \mathrm{Mo}$ steel, classified by the ASTM A387-79b standard ${ }^{11}$ as Grade P11 SA335 (Table 1).

The behavior of the material was analyzed under two conditions: In Service-Aged Material (ISAM) - without additional thermal effect - and In Service-Aged Material Weldment (ISAMW) resulting from the laboratory simulation of the industrial weld repair process, using the same Welding Procedure Specification (WPS) as that applied industrially.

The cylindrical sample taken from a pipe was fixed and girth welded in position $6 \mathrm{G}$. The joint was prepared according to the V-type with root face (1.5 mm height).

Root welding was performed with the TIG process: DCEN, 100-130 A, 10-15 V, 50-100 mm/min. The next 3 layers were applied with electrode AWS E-8018-B2 $3.5 \mathrm{~mm}$ with: DCEP, 100-140 A, $150-200 \mathrm{~mm} / \mathrm{min}$. Preheating to $200^{\circ} \mathrm{C}$ and a maximum temperature of $300{ }^{\circ} \mathrm{C}$ between pass were applied.

The PWHT $\left(1.5 \mathrm{~h}\right.$ at $\left.700{ }^{\circ} \mathrm{C}\right)$ was performed in a muffle furnace with a heating rate of $200{ }^{\circ} \mathrm{C} / \mathrm{h}$ and in furnace cooling.

Using $\mathrm{X}$ rays radiography after the welding and PWHT in was not found any weld defect.

The remanent life was predicted based on the rupture time estimated for the service conditions $\left(480{ }^{\circ} \mathrm{C}\right.$, under a stress of $\left.94 \mathrm{MPa}\right)$ and was obtained by extrapolating the results of the creep rupture test.

The creep rupture tests were carried out with a constant load in an air atmosphere, according to the ASTM E-139 standard $^{12}$. With the aim of obtaining cracking times between 10 and 10.000 hours the nominal stress varied from 100 to $175 \mathrm{MPa}$ and the temperature ranged from 525 to $625^{\circ} \mathrm{C}$. Cylindrical samples having a $6 \mathrm{~mm}$ diameter and $36 \mathrm{~mm}$ length were used, to which were added the length corresponding to the cross-section of the weld line, in the case of the welded joints. The samples were taken from the central part of the pipe in the cross-section direction of the weld.

The results of these tests were analyzed by multiple linear regressions to obtain the parameters of the model, which served as the basis for estimating the rupture time under service conditions (Equation 1, converted into a linear equation using the logarithmic effect).

$$
\mathrm{t}_{\mathrm{r}}=\mathrm{A} \sigma^{\mathrm{n}} \exp (-\mathrm{Q} / \mathrm{T})
$$

where: $\mathrm{t}_{\mathrm{r}}=$ rupture time $(\mathrm{h}) ; \sigma=$ nominal stress $(\mathrm{MPa}) ; \mathrm{T}=$ temperature $(\mathrm{K}) ; \mathrm{A}, \mathrm{n}$; and $\mathrm{Q}=$ constants of the model.

The metallographic analysis (SEM and TEM) was done in ISAM condition (cross-section of the pipe) and in ISAMW condition (cross-section of the weldment). Specimens for SEM analysis were prepared by grinding and polishing to a $1 \mu \mathrm{m}$ finish, and etching in a $2 \%$ NITAL. The analysis was conducted with a LEICA-Stereoscan 440 microscope. Two-steep carbon extraction replicas and thin foils

Table 1. Chemical composition of the pipeline material (weight $\%$ ).

\begin{tabular}{cccccccccc}
\hline $\mathrm{C}$ max & $\mathrm{Si}$ & $\mathrm{Mn}$ & $\mathrm{P} \max$ & $\mathrm{S} \max$ & $\mathrm{Cr}$ & $\mathrm{Mo}$ & $\mathrm{V}$ & $\mathrm{Ti}$ & $\mathrm{V}$ \\
\hline 0.12 & 0.38 & 0.41 & 0.03 & 0.03 & 1.24 & 0.49 & 0.019 & 0.024 & $<0.02$ \\
\hline
\end{tabular}


were analyzed in a PHILIPS/CM-120 TEM, equipped with energy dispersive $\mathrm{X}$ ray spectroscopy and operated at $120 \mathrm{kV}$.

\subsection{Results and discussion}

During the in service weld repair process, the component is exposed to two thermal cycles: one associated with the welding process - which gives rise to the regions known as Weld Metal and HAZ - and the other associated with the localized PWHT - which acts additionally on the Weld Metal and HAZ (WM + PWHT and HAZ + PWHT regions) - and also originates a new zone (ISAM $+\mathrm{PWHT}$ region, that is thermally affected only by the PWHT) located between the HAZ and the Weld Repair Unaffected Base Metal (ISAM condition).

Therefore, concerning the thermal cycles, the weld repair and its metallurgical implication, the ISAMW condition in the crosssection of the weldment has three regions: (1) WM + PWHT; (2) HAZ + PWHT; and (3) PWHT.

Figure 1 illustrates the results of the creep test for each condition (ISAM and ISAMW). It is worth noting that the rupture during the creep test of all the welded samples occurred, in every case, in that region affected only by the PWHT. This indicates that the creep strength in this region (PWHT region) is lower than that of the WM + PWHT and HAZ + PWHT regions, for which reason the characterization of the microstructure of the ISAMW condition was limited to this region.

Table 2 lists the value of each parameter of the model (Equation 1) for each condition. Based on the statistical analysis (lack of fit and ANOVA), the model was considered valid with a $95 \%$ confidence level and the error of the estimated values was less than $5 \%$, allowing to state that, from the predictive standpoint, the model is functional in both cases.

For the stress allowed at the service temperature (94 MPa at $480{ }^{\circ} \mathrm{C}$ ), this analysis yields the following ratio between the rupture times estimated according to the model for each condition:

$$
\mathrm{t}_{\mathrm{r} \text { ISAM }} / \mathrm{t}_{\mathrm{r} \text { ISAMW }}=3.6
$$

where:

$\mathrm{t}_{\mathrm{r} \text { ISAM }}$ - rupture time estimated for the ISAM condition, and $\mathrm{t}_{\mathrm{r} \text { ISAMW }}$ - rupture time estimated for the ISAMW condition.

According to Equation 2, the weld repair had a markedly detrimental effect on the creep behavior of the pipe analyzed here, since it caused in significant reduction in the estimated rupture time for service conditions (a factor of 0.28), implying that the weld repair reduces the remanent life by approximately $70 \%$.

The microstructural analysis of the ISAM condition indicated a band structure with laminar pearlite (approximately 30\%) and ferrite (Figure 2a) with fine, regular and homogeneous sized intragranular precipitation and coarse intergranular precipitates (Figure $2 b$ and $2 \mathrm{c})$.

In the PWHT region of the ISAMW condition the microstructure remained similar to that of the ISAM condition, although the fine precipitates are no longer of homogeneous size and new intragranular precipitates appear longer, with a 4 to 5 length/width ratio (Figure 3).

According to the chemical composition, which was determined by microanalysis of several intragranular particles in each condition, and to the electron diffraction analysis (Figure 4), the uniformly

Table 2. Value of model parameters (Equation 1) for each condition.

\begin{tabular}{clcc}
\hline Parameter & ISAM condition & ISAMW condition \\
\hline $\mathrm{A}$ & $10^{-15,3}$ & -6.4 \\
$\mathrm{n}$ & -5.4 & 20586 \\
model & 24749 & $\log \left(\mathrm{t}_{\mathrm{r}}\right)=-15.3-5.4 \log (\sigma)-24749 / \mathrm{T}$ & $\log \left(\mathrm{t}_{\mathrm{r}}\right)=-8.5-6.4 \log (\sigma)-20586 / \mathrm{T}$ \\
\hline
\end{tabular}



(a)

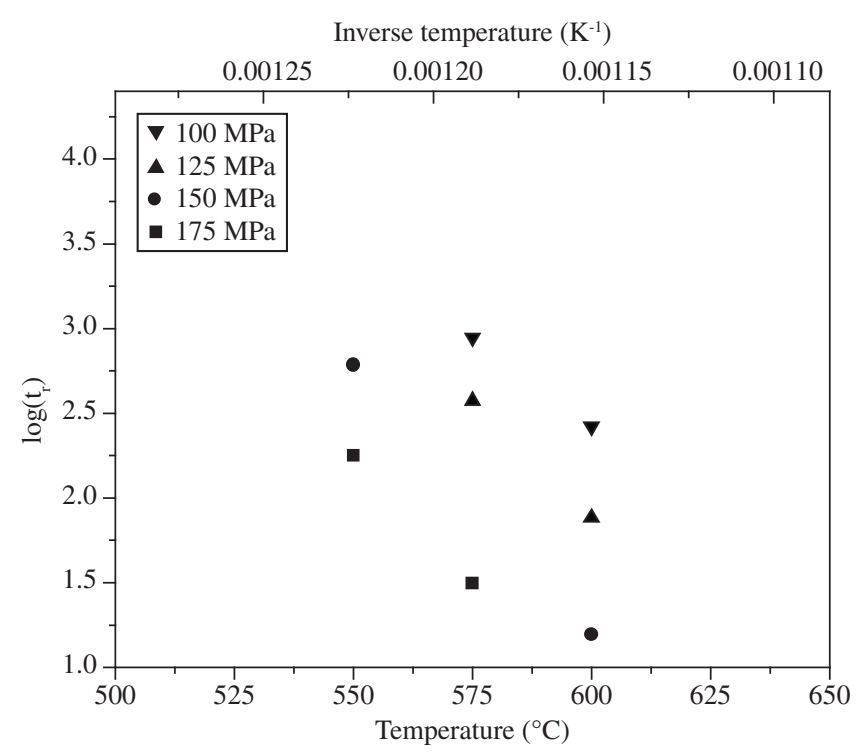

(b)

Figure 1. Results of the creep test: a) ISAM condition; and b) ISAMW condition. 




(a)

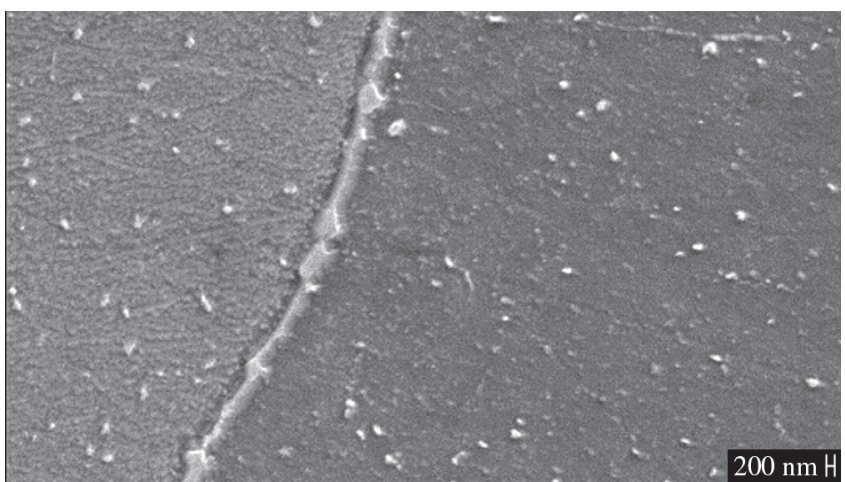

(b)

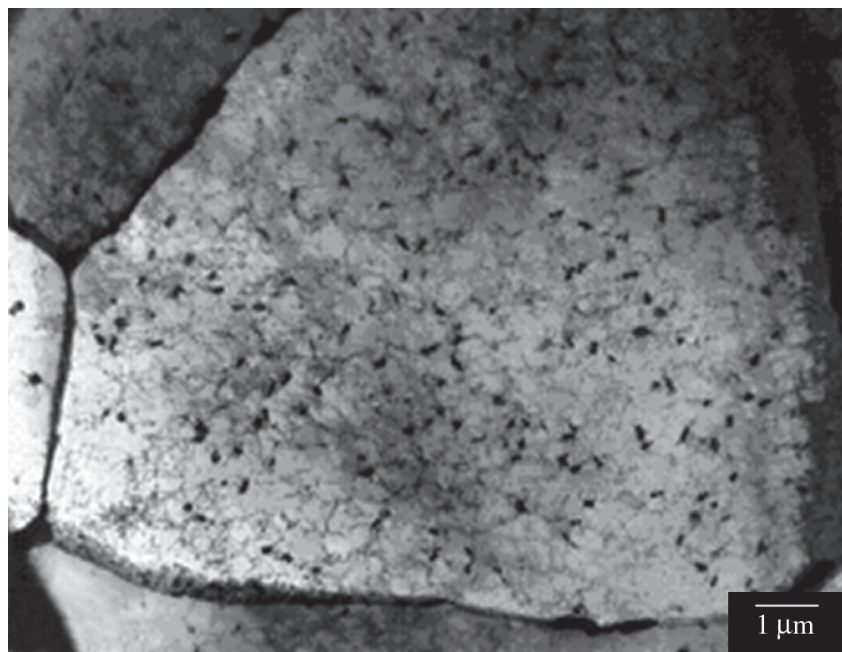

(c)

Figure 2. a) Optical microscopy image showing the ferrite-pearlite structure; and b,c) SEM and TEM images showing the fine intragranular and coarse intergranular precipitation in the ISAM condition (cross-section of the pipe).

shaped fine precipitates in both conditions were of the $\mathrm{Mo}_{2} \mathrm{C}$ type. This type of precipitate was also observed by other researchers in service-aged 21/4Cr1Mo steel steam pipelines (Norris and Parker ${ }^{13}$ ) and in new pipelines (Yang et al. ${ }^{14}$ ). In these two cases, the authors identified the intragranular precipitates as $\mathrm{M}_{2} \mathrm{C}$.
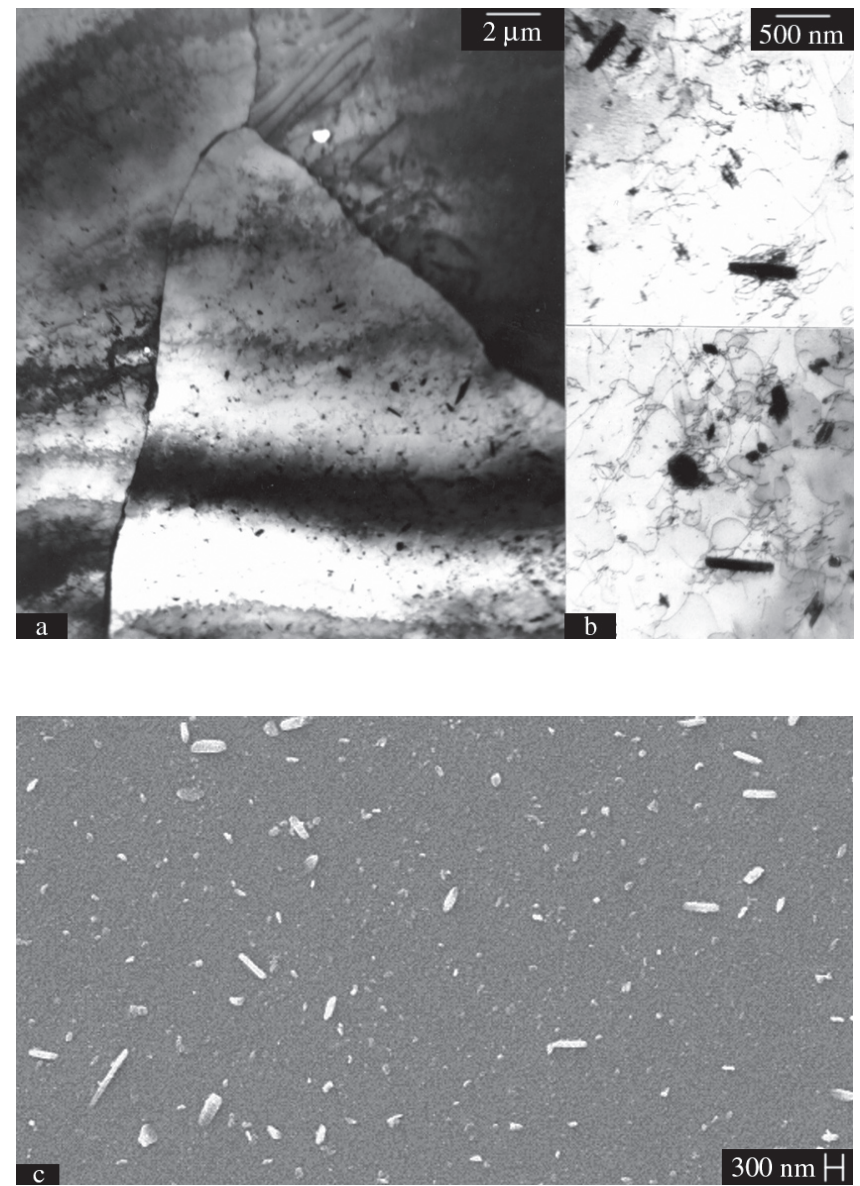

Figure 3. TEM and SEM images, respectively, showing the presence of both elongated and fine heterogeneous sized intragranular precipitates in the ISAMW condition (cross section of the weldment, PWHT region).

In the case of the long particles, an analysis similar to the previous one (Figure 5) indicated that they are of the $\mathrm{Fe}_{2} \mathrm{MoC}$ type. This type of precipitate was also observed by Dyson and Andrews ${ }^{15}$ in $\mathrm{Fe}-\mathrm{Mo}-\mathrm{C}$ steel systems. According to these authors, the precipitation of $\mathrm{Fe}_{2} \mathrm{MoC}$ occurs when the atomic percent $\mathrm{Mo}: \mathrm{C}$ ratio in solution is 1.22 and it requires only a $1 \% \mathrm{Cr}$ content in solution to prevent this occurrence.

The fact that intragranular $\mathrm{Mo}_{2} \mathrm{C}$ particles of homogeneous size were found in the ISAM condition and heterogeneous sized particles in the ISAMW condition suggests that the phenomenon of Ostwald ripening occurred during the weld repair (the smaller particles dissolve in the matrix providing the selective growth of the larger particles). This fact, and the $\mathrm{Fe}_{2} \mathrm{MoC}$ precipitation observed here, indicates that there was probably a loss of solute through the matrix and an increase in the distance between $\mathrm{Mo}_{2} \mathrm{C}$ particles. According to Klueh ${ }^{16}$, both these effects, due to their negative influence on the mechanisms governing the increase of creep resistance by precipitation and by solid solution interaction, are responsible for the loss of creep resistance and, hence, for the reduction of remanent life post weld repair.

\section{Conclusions}

The specialized literature reveals a controversy regarding the effect of weld repair on the performance of service-aged low alloy CrMo steel steam pipes. Not withstanding this polemic, the results 

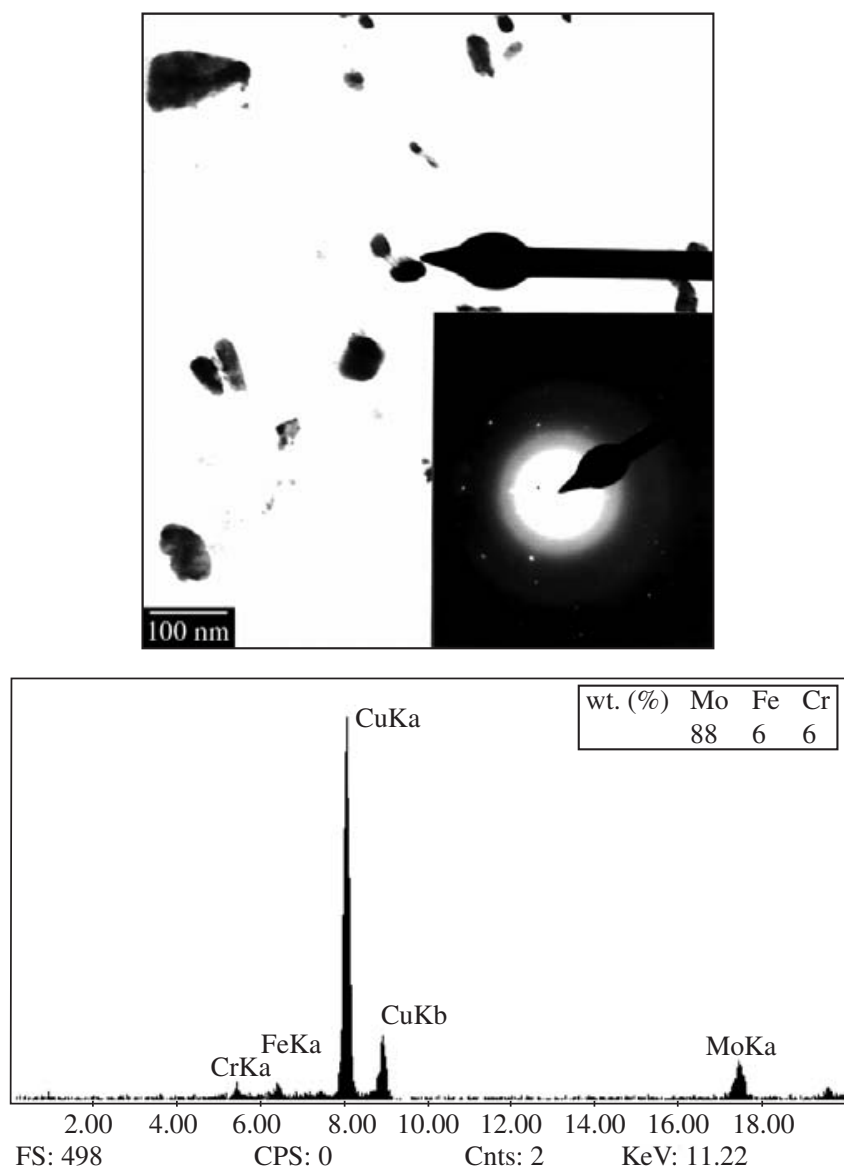

Figure 4. Representative result of the electron diffraction analysis of a selected area (carbide extraction replica) and of the EDS spectrum of uniform fine $\mathrm{M}_{2} \mathrm{C}$-type precipitates.

of the study reported here, which involved a weld repair carried out on a $1 \frac{1}{4} \mathrm{Cr}^{1} / 2 \mathrm{Mo}$ steel steam pipe aged by 20 years of service, indicate that the remanent life can be reduced by as much as $70 \%$ as a result of the weld repair. The fundamental causes for the creep resistance and remanent life reduction were found to be loss of solute by the ferrite and increased distance between precipitates occurring as a consequence of $\mathrm{Fe}_{2} \mathrm{MoC}$ precipitation induced by PWHT.

\section{Acknowledgments}

The authors would like to thank the Brasilian agencies CAPES and FAPESP for financial support to this work.

\section{References}

1. Viswanathan R. Damage mechanisms and life assessment of high temperature components. Ohio: ASM International; 1989.

2. Gandy W, Viswanathan R, Findlan S. Performance of weld repairs on service aged 2,25Cr1Mo girth weldments utilizing conventional postweld heat treatment and temperbead repair techniques. Weld repair technology. Workshop... Pressure Vessel Research Council/Edison Welding Institute; Jan. 31 - Feb. 1, San Diego; 1996.

3. Viswanathan R, Gandy D, Findlan, S. Advanced weld repair technology extends plant life. Power Engineering. 1996; 100(13):1-4.

4. Viswanathan R, Gandy D, Findlan S. Performance of repair welds on service-aged girth welds. Journal of Pressure Vessel Technology. 1997; 119(11):1-9.
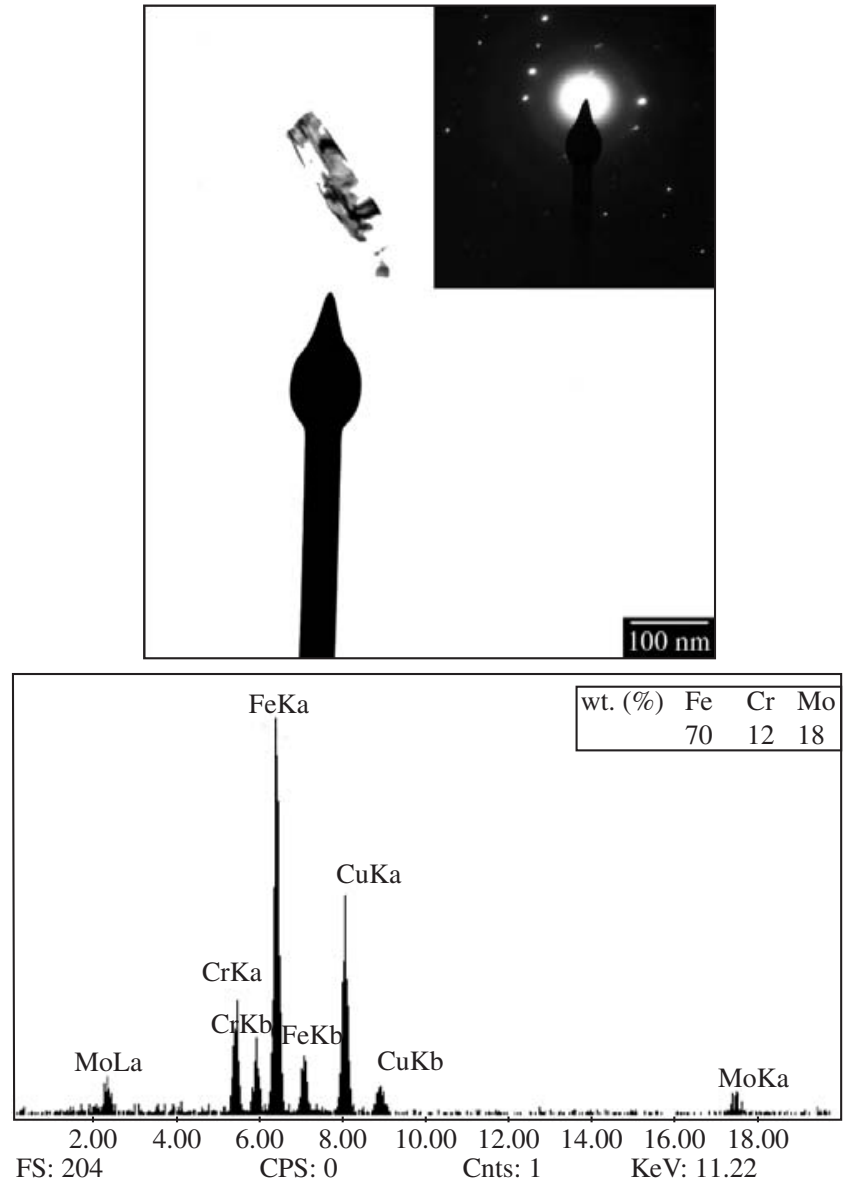

Figure 5. Representative result of the electron diffraction analysis of a selected area (carbide extraction replica) and of the EDS spectrum of elongated $\mathrm{Fe}_{2} \mathrm{MoC}$-type precipitates.

5. Lunding C, Liu P, Qiao P, Zhou G, Khan K, Prager M. An Experimental Study of Causes and Repair of Cracking of 11/4Cr 1/2Mo Steel Equipment. American Petroleum Institute. API Publication. 1996; 938. 215p. may.

6. Etienne F, Heerings J, Wortel C. Weldability and assessment of remanent life of repair welds in thick walled headers. In: Proceedings of VGB Conference. Remanent service life; 1992 july 6-7; Mannheim: Germany. 1992. p. 33.1-33.25.

7. Arnswald W, Blum R, Neubauer B, Poulsen K. Remaining life affected by welds. In: JSME/IMechE/ASME/ASTM, editors. Creep: International Conference: Papers. Proceedings of International Conference on Creep; 1986 April; Tokyo: Japan; 1986. p. 367-372.

8. Westwood H. Axial creep tests on 1.25Cr0.5Mo steam pipe weldments. In: Bicego V, Nitta A, Viswanathan R, editors. Materials Aging and Component Life Extension. Proceedings of International Symposium on Materials Aging and Component Life Extension; 1995, October 10-13; Milan: Italy; Engineering Materials Advance Service. 1995. p. 240245.

9. Parker J, Stratford G. Effect of heat treatment on creep and fracture behavior of 1,25Cr0,5Mo steel. Materials Science and Technology. 1995; 11(12):1267-1273.

10. Shiga C, Gotoh A, Kojima T, Horii Y, Fukada Y, Ikeuti K, et al. State of the art review on the effect of PWHT on properties of steel weld metal. Welding in the World. 1996; 37(4):163-176.

11. Anual Book of ASTM Standars. Standard specification for pressure vessel plates, alloy steel, chromium - molybdenum. ASTM A387-79b. 1982, p. 359-364. 
12. Anual Book of ASTM Standars. Standard practice for creep, creeprupture, and stress-rupture tests of metallic materials. ASTM E-139. p. 309-319, 1990.

13. Norris D, Parker J. The effect of microstructure on fracture mechanism of 2,25Cr1Mo low alloy steel. Part B: The influence of carbides. Journal of Pressure Vessels and Piping. 1996; 67(11):329-337.
14. Yang R, Huang Y, Yang N, Horng L. Microstructural examination of 2.25Cr1Mo steel pipes after extended service. Materials Characterization. 1993; 30(2):75-88.

15. Dyson D, Andrews K. The structure and metallurgical significance of the iron - molybdenum carbide $\mathrm{Fe}_{2} \mathrm{MoC}\left(\mathrm{M}_{\mathrm{a}} \mathrm{C}_{\mathrm{b}}\right)$. Journal of the Iron and Steel Institute. 1964; 202(4):325-329.

16. Klueh L. Interaction solid solution hardening in $2.25 \mathrm{Cr} 1 \mathrm{Mo}$ steel. Materials Science and Engineering. 1978; 35(2):239-253. 